\title{
REVIEW
}

\section{Singling out genetic disorders and disease}

Martine De Rycke*

\begin{abstract}
Preimplantation genetic diagnosis ( $P G D$ ) involves testing of single cells biopsied from oocytes and/ or embryos generated in vitro. As only embryos unaffected for a given genetic condition are transferred to the uterus, it avoids prenatal diagnosis and termination of pregnancy. Follow-up data from PGD pregnancies, deliveries and children show an acceptable live birth rate and, so far, no detrimental effects of the procedure have been observed. Of course, the long-term health outcome is currently unknown. PGD was first performed in 1990 and remained an experimental procedure for a number of years. Now, two decades later, it is regarded as an established alternative to prenatal diagnosis: its use has expanded, the range of applications has broadened, and continuous technical progress in single-cell testing has led to high levels of efficiency and accuracy. The current gold standard methods (single-cell multiplex-PCR for monogenic diseases and interphase fluorescence in situ hybridization for chromosomal aberrations) are being replaced by single-cell whole genome amplification and array technology. These generalized methods substantially reduce the prePGD workload and allow more automated genomewide analysis. The implementation of laboratory accreditation schemes brings the field at the same level of routine diagnostics. This article reviews the state of the art and considers indications, accuracy and current technical changes in the field of PGD.
\end{abstract}

\section{Introduction}

Preimplantation genetic diagnosis (PGD) is an alternative to prenatal diagnosis involving the biopsy and genetic testing of single cells from in vitro obtained oocytes and/ or preimplantation embryos. Only embryos shown to be free of the genetic defect under study are transferred to

*Correspondence: martine.derycke@uzbrussel.be

Centre for Medical Genetics, Universitair Ziekenhuis Brussel, Laarbeeklaan 101, Brussels, Belgium the uterus of the patient. PGD is performed for couples at high risk of transmitting a genetic condition to their children; it offers the advantage of circumventing an invasive prenatal diagnosis and therapeutic abortion.

Preimplantation genetic screening (PGS) involves the selection of euploid embryos to improve in vitro fertilization (IVF) results and to avoid pregnancies with chromosomal abnormalities [1]. Considering the increasing risk for aneuploidy with advanced maternal age and findings of high aneuploidy rates in spontaneous abortions, PGS has been offered to specific IVF patient groups: patients of advanced maternal age and patients with recurrent IVF failure or repeated miscarriages (not due to translocations). For many years, PGS using fluorescence in situ hybridization (FISH) for 5 to 12 chromosomes has been applied worldwide but without real validation of its efficiency. In recent years, several randomized controlled trials have failed to show a benefit for PGS, as summarized in the meta-analysis by Checa and colleagues [2]. Biological (embryonic mosaicism) and technical (limitations of FISH and negative impact of cleavage-stage biopsy) arguments were proposed to explain the lack of benefit. Further clinical practice now awaits new randomized controlled trials to prove that PGS with biopsy at other stages, and using new array methods with full chromosome analysis, improves live birth rates and reduces miscarriage rates [3]. PGD and PGS rely on the same technology, but since PGS is offered to (sub)fertile couples without genetic diseases, it is mostly outside the scope of this review.

PGD developed in the wake of human IVF and PCR technology. The first children born after PGD were reported by Handyside et al. in 1990 [4]. In these initial cycles, PCR was used for gender determination in families with X-linked diseases. Later, FISH became the standard method for sexing, and also for chromosomal aberrations, while PCR-based methods were used for the detection of single gene defects. It is essential that these techniques are adapted to the single-cell level and are thoroughly validated before clinical application.

PGD requires a multidisciplinary team with a close collaboration and excellent communication between the assisted reproduction unit and the medical genetics unit. Preferentially, both units work within the same institute. Alternatively, transport PGD can be set up, and IVF 
treatment (hormonal stimulation, oocyte retrieval and in vitro fertilization, embryo culture and embryo transfer) is carried out at a satellite assisted-reproduction unit. Only the biopsied embryonic cell samples are transported, often over long distances, to a genetics unit specializing in single-cell diagnosis.

Extensive data on PGD cycles, pregnancies, deliveries and children have been collected by the European Society for Human Reproduction and Embryology (ESHRE) PGD consortium since 1997 and, although not worldwide, the data sets offer comprehensive insights into this particular field of single-cell testing [5].

\section{Indications for preimplantation genetic diagnosis}

The main indications for PGD are chromosomal abnormalities, X-linked disorders and single gene or monogenic disorders. The majority of PGD cycles for chromosomal abnormalities are aimed at reciprocal and Robertsonian translocations, while cases with inversions or insertions are less frequent. For the monogenic disorders, PGD was initially applied for the same indications as in prenatal diagnosis. According to the latest ESHRE PGD consortium data, the most common indications for autosomal recessive disorders are cystic fibrosis, spinal muscular atrophy and hemoglobinopathies [6]. For the autosomal dominant disorders, myotonic dystrophy type 1 , neurofibromatosis and Huntington's disease are the most frequently requested indications; for the X-linked disorders, PGD is mainly carried out for Duchenne's muscular dystrophy, hemophilia and fragile X syndrome. Sexing with FISH has been most frequently used for Xlinked disorders but more and more specific DNA diagnoses have been developed. Specific DNA diagnosis has important advantages: first, healthy male embryos are not discarded; and second, female carriers can be identified and excluded from transfer or not, according to the wishes of the patient and the policy of the center.

PGD is currently available for more than 200 monogenic diseases and has lately also been applied for indications, such as cancer predisposition syndromes and other late-onset diseases, for which prenatal diagnosis is ethically difficult $[7,8]$. For cancer predisposition syndromes that are not fully penetrant and for which some form of therapeutic measures may be available, prenatal diagnosis and termination of pregnancy remain controversial. As the preimplantation embryo is often considered as having less moral value than a fetus, PGD seems a more acceptable option.

Another more recent indication is human leucocyte antigen (HLA) typing of preimplantation embryos to select an embryo that is HLA compatible with an affected sibling. At birth, hematopoietic stem cells from the cord blood of the saviour baby are then used to transplant the sick sibling. HLA typing alone is carried out for acquired diseases, such as severe aplastic anemia, or HLA typing is combined with the detection of mutations underlying immunodeficiencies and hemoglobin disorders [9- 11]. The major ethical objection here is that the future child may be regarded as an instrument and not as an autonomous person. This concern was studied in depth and it was concluded that considering the efforts of the parents to cure the sick child and their wish for another child, it is unlikely that they would treat the saviour child solely as a donor. In addition, it is universally accepted to rely on an existing HLA-compatible child as a donor of hematopoietic stem cells [12].

So far, few clinical cycles have been carried out for families carrying heteroplasmic mitochondrial $(\mathrm{mt}) \mathrm{DNA}$ mutations [13-15]. The genetics of mtDNA is quite complex and the proportion of mutant mtDNA transmitted from mother to offspring will vary due to a genetic bottleneck in the oocytes [16]. It is another ethically difficult indication, as the possibility exists that there are no zero-mutation embryos for transfer but just embryos with a low mutation load (that is, the ratio of mutant to normal mtDNA) under a certain disease-specific threshold, meaning that the risk for an affected child is not eliminated but only reduced. PGD for mtDNA mutations can only be offered reliably when certain criteria are fulfilled: a close correlation between the mutation load and disease severity is a first requirement; second, there should be no change in mutation load with time; and third, mutant mtDNA should be uniformly distributed over all blastomeres of the cleavage-stage embryo [17]. For many mtDNA mutations the latter information is not available. Therefore, it is recommended to develop PGD within a scientific research protocol and to counsel prospective parents adequately and inform them that a first PGD cycle may be carried out merely to gather information on the reliability of PGD [18].

\section{Assisted reproductive technology and biopsy}

The first step in a PGD cycle is controlled ovarian hyperstimulation, aimed at obtaining a large cohort of mature oocytes. The aspirated oocytes are denuded of surrounding cumulus cells before IVF occurs. Intracytoplasmic sperm injection is preferred over regular IVF, regardless of the sperm quality, in order to avoid residual sperm adhering to the zona pellucida after IVF. Remaining cumulus or sperm cells may lead to contamination when PCR is used for diagnosis [19].

The biopsy procedure involving breaching of the zona pellucida and removal of the cell(s) can be carried out at different developmental stages [20]. Polar body (PB) biopsy from oocytes (first PB from metaphase II oocytes and second $\mathrm{PB}$ after normal fertilization) is a first possibility [21]. As PBs do not contribute to normal fertilization or embryonic development, their removal 
has no detrimental effect. In countries where embryo selection is forbidden, PB biopsy is the only legal option as testing can take place before syngamy, which is the moment considered as the beginning of an embryo. The main disadvantage is that $\mathrm{PB}$ analysis can only evaluate the maternal genetic contribution. The ESHRE PGD consortium data collection indicates that cleavage-stage biopsy at day 3 is used in the majority of PGD cycles [6]. At this eight-cell stage, embryo compaction has not started yet and cells are considered to be totipotent. The zona pellucida opening is mostly carried out with a noncontact diode infrared laser and one or two nucleated blastomeres are aspirated [22]. The impact of the random removal of one or two embryonic cells on further development and implantation potential is highly debated. In a recent prospective analysis of a cohort of single-embryo transfers, the authors demonstrated that the live birth rate after one-cell removal from eight-cell embryos (37.4\%) is similar to the rate of a control intracytoplasmic sperm injection group without biopsy (35.0\%), but significantly higher than the rate of the twocell biopsy study group (22\%). It is therefore recommended to biopsy one cell, provided that an accurate and reliable diagnosis method is in place [23]. Another limitation of cleavage-stage biopsy is the high chromosomal mosaicism rate that seems inherent at this developmental stage and probably evolves to lower rates at the blastocyst stage via self-correction [24]. Trophectoderm (TE) biopsy at day 5 is a fast emerging biopsy approach. Some reports suggest that it may yield substantially higher implantation and live birth rates than cleavage-stage biopsy [25-27]. About 4 to 20 extra-embryonic TE cells are aspirated and the inner cell mass, from which the fetus will develop, is kept intact. This is one advantage compared with cleavage-stage biopsy; another advantage is that multiple cells are available for genetic testing, and this may improve diagnostic accuracy. The drawbacks of TE biopsy are that it requires a successful embryo culture system with high blastocyst rates and it leaves limited time for genetic analysis. The time problem may be solved by freezing the blastocysts, relying on efficient vitrification and thaw-survival protocols, and transferring them later in a natural cycle.

After biopsy, (single) cells are washed and either fixated for FISH analysis or tubed and lysed for amplification. Amplification reaction components are added directly to the lysed cells without prior DNA purification.

\section{Single-cell genetic testing for monogenic disorders}

In principle, any monogenic disease for which the chromosomal locus has been identified can be diagnosed at the single-cell level. The golden standard today is fluorescent multiplex PCR in which one of each primer pair is fluorescently labeled, allowing subsequent detection of PCR fragments on an automated sequencer. In indirect tests, multiple short tandem repeat markers are co-amplified together in one reaction (linkage-based strategy); for direct testing, markers are combined with specific mutation(s). The main advantage of linkagebased testing over mutation-specific testing is that the single-cell protocols can be used for several couples, independent of the mutation they carry. This saves time, resources and manpower in pre-PGD workups for diseases for which many private mutations have been identified. The use of polymorphic markers implicates that during pre-PGD work up, informativity and segregation tests are performed on DNA samples of the couple and family members to establish which alleles of the informative markers segregate with the mutation. Different strategies of PCR and allele discrimination have been developed for mutation detection over recent years, and the most important ones are: amplification refractory mutation system [28], endonuclease restriction [29], minisequencing [30] and quantitative real-time PCR [26]. PCR-based protocols with short tandem repeat markers have recently also been applied in PGD cycles for structural chromosome abnormalities, in which FISH has been traditionally the preferred method [31,32]. A major bottleneck with PCR assays is that the single-cell adaptation and validation part of the pre-PGD work up has to be repeated with every new DNA locus. In recent years, the use of single-cell whole genome amplification (WGA) as a universal step has been demonstrated to be a practical and efficient alternative to single-cell PCR. The first WGA methods were PCR-based and suffered from incomplete genome coverage and amplification bias, but the more recent methods are markedly better [33]. One method is multiple displacement amplification that relies on isothermal strand displacement amplification with Phi29 DNA polymerase. This method is very straightforward but requires high-quality DNA as the template, and yields relatively high allele drop-out (ADO) and preferential amplification rates of $25 \%$ on average [34]; this is about five times higher than with fluorescent multiplex PCR. Other WGA methods involve somewhat more complex protocols with DNA fragmentation and library formation prior to amplification; they even amplify low-quality DNA, and ADO rates are approximately $10 \%$ [35]. Single-cell WGA generates micrograms of amplified DNA, which is sufficient for several downstream applications. Multiple standard PCR assays may be performed for haplotyping in case of monogenic diseases [36]. Haplotyping can also be combined with array comparative genomic hybridization $(\mathrm{aCGH})$ for the detection of chromosomal imbalances. These strategies are already clinically applied in some centers. Further improvement and generalization will come from the introduction of high-density single nucleotide polymorphism 
(SNP) arrays, which enable evaluation of DNA haplotyping and chromosomal constitution on the same platform. The validation of these SNP arrays is ongoing $[37,38]$. The implementation of these new technologies will reduce the procedures substantially and introduce automation. On the other hand, these arrays will generate a tremendous amount of genetic data - for instance, on disease susceptibility genes - and it is expected that this will entail many ethical discussions and challenges for genetic counseling.

\section{Single-cell genetic testing for chromosomal aberrations}

The majority of PGD cycles for chromosomal aberrations are performed for translocations. Balanced translocation carriers have a high risk for producing chromosomally unbalanced gametes and present with infertility, repeated spontaneous abortions and unbalanced offspring. With FISH, fixated cells are hybridized using chromosome-specific DNA probes, which are labeled with different fluorochromes. Probe selection is based on the breakpoints of the specific translocation and chromosomes involved, and should allow detection of all possible segregation patterns. FISH has a number of technical limitations and it is gradually replaced by aCGH. Here, whole genome amplified DNA of the test single-cell(s) is labeled with a green fluorochrome, while a red fluorochrome is used for the control sample. Both samples are mixed and hybridized to either a normal metaphase chromosome spread or, in case of aCGH, to DNA sequences specific to human chromosomes spotted on an array. A computerized system allows analysis of the ratios between both fluorochromes for each chromosome and detection of imbalances. As metaphase comparative genomic hybridization $(\mathrm{CGH})$ at the single-cell level requires several days for analysis, groups that have presented clinical application of CGH in PGD have to resort to either polar body analysis [39] or cryopreservation of the embryos [40,41]. As aCGH has a lower hybridization time, it can be performed within the time frame of PGD. Other advantages over metaphase $\mathrm{CGH}$ are the higher resolution and the important automation [42]. aCGH following multiple displacement amplification has been preclinically validated in single lymphoblasts, fibroblasts and blastomeres of translocation carriers [43], and clinical data have been published for PGS applications [44]. Compared with FISH, aCGH provides a generalized platform, circumventing pre-PGD testing of FISH probes with every new translocation. aCGH, as well as SNP arrays, yields information on genome-wide copy number variation, but only SNP arrays offer simultaneously genotype information and present a universal platform for both chromosomal aberrations and monogenic diseases. Therefore, SNP arrays are regarded as the most promising future strategy for PGD.

\section{Accuracy}

Single-cell DNA amplification is technically demanding because of the small amount of non-purified DNA at the start, and inherent pitfalls of contamination and ADO, which can lead to misdiagnosis. ADO is defined as the random failure of amplification for one of two alleles in a heterozygous cell. The use of optimized cell lysis and DNA amplification conditions, along with sensitive detection systems, should reduce ADO to a minimum. Contamination is minimized by taking a number of prevention measures (see best practice guidelines). The application of multiplex PCR protocols further assists in monitoring problems of contamination and ADO in addition to mutation detection, making these assays highly accurate.

A recent theoretical study on the accuracy of FISH showed that the technology has the potential of high accuracy for sexing and for translocations, but not in the case of aneuploidy screening [45]. Apart from technical errors such as ADO and contamination, other possible causes for misdiagnosis involve intrinsic sample quality, such as chromosomal mosaicism, and human errors, such as mislabeling, incorrect embryo transfer or erroneous segregation analysis. According to the PGD consortium data, low error rates have been observed for both DNA-amplification-based cycles $(0.5 \%)$ and FISHbased cycles (0.1\%) [46].

\section{Quality control and assurance}

PGD is still relatively unregulated compared with routine genetic testing. In order to better standardize single-cell testing and to achieve high quality levels, guidelines for best practice have been designed by the ESHRE PGD consortium and by the Preimplantation Genetic Diagnosis International Society [47-49]. In addition, four new extensive guidelines on different aspects of PGD (organization of a PGD center, FISH-based testing, amplificationbased testing and biopsy) are in preparation.

A powerful method for quality assurance is accreditation. In 2008, only 33\% of 53 European PGD centers had achieved or were preparing for accreditation [50]. Many countries and international authorities now recommend PGD centers to initiate the accreditation process; that is, to be committed not only to reach the standards set by the accrediting body but also to continuously enhance the quality of the services.

Two programs of external quality assessment (EQA), a key element of quality assurance [51,52], have been initiated recently. The UK National External Quality Assessment Service [53], in collaboration with the ESHRE PGD consortium, has set up EQA programs for 
PGD for monogenic diseases, while the FISH-based PGD EQA program is run by the Cytogenetics European Quality Assessment [54].

\section{Conclusions}

In the past two decades, PGD has evolved from an experimental procedure to a widely accepted alternative for prenatal diagnosis that is applied to an expanding range of indications. Non-stop technical improvements have provided reliable and accurate single-cell assays for both chromosomal abnormalities and monogenic disorders. As protocols are often family specific, their development is labour intensive and time consuming and can be carried out in specialized laboratories. The introduction of powerful array technologies following universal whole genome amplification will reduce the workload and allow automation. Together with the implementation of accreditation schemes, this will lead to improved standardization and uniformity in the complex process of PGD.

\section{Abbreviations}

aCGH, array comparative genomic hybridization; $\mathrm{ADO}$, allele drop-out; $\mathrm{CGH}$, comparative genomic hybridization; EQA, external quality assessment; ESHRE, European Society for Human Reproduction and Embryology; FISH, fluorescence in situ hybridization; HLA, human leucocyte antigen; IVF, in vitro fertilization; $\mathrm{mt}$, mitochondrial; $\mathrm{PB}$, polar body; $\mathrm{PCR}$, polymerase chain reaction; $P G D$, preimplantation genetic diagnosis; $P G S$, preimplantation genetic screening; SNP, single nucleotide polymorphism; TE, trophectoderm; WGA, whole genome amplification.

\section{Competing interests}

The author declares that she has no competing interests.

\section{Acknowledgements}

I thank Pascale De Becker for providing feedback and edits on the manuscript.

Published: 6 October 2010

\section{References}

1. Verlinsky Y, Kuliev A: Preimplantation diagnosis of common aneuploidies in fertile couples of advanced maternal age. Hum Reprod 1996, 11:2076-2077.

2. Checa MA, Alonso-Coello P, Solà I, Robles A, Carreras R, Balasch J: IVF/ICSI with or without preimplantation genetic screening for aneuploidy in couples without genetic disorders: a systematic review and meta-analysis. J Assist Reprod Genet 2009, 26:273-283.

3. Harper J, Coonen E, De Rycke M, Fiorentino F, Geraedts J, Goossens V, Harton G, Moutou C, Pehlivan BudakT, Renwick P, Sengupta S, Traeger-Synodinos J, Vesela K: What next for preimplantation genetic screening (PGS)? A position statement from the ESHRE PGD Consortium Steering Committee. Hum Reprod 2010, 25:821-823.

4. Handyside AH, Kontogianni EH, Hardy K, Winston RM: Pregnancies from biopsied human preimplantation embryos sexed by Y-specific DNA amplification. Nature 1990, 344:768-770

5. The ESHRE PGD consortium [http://www.eshre.eu/01/default. aspx? pageid $=201]$

6. Harper J, Coonen E, De Rycke M, Harton G, Moutou C, Pehlivan T, TraegerSynodinos J, Van Rij M, Goossens V: ESHRE PGD consortium data collection $\mathrm{X}$ : Cycles from January to December 2007 with pregnancy follow-up to October 2008. Hum Reprod 2010, in press.

7. Verlinsky Y, Rechitsky S, Verlinsky O, Xu K, Schattman G, Masciangelo C, Ginberg, N, Strom C, Rosenwaks Z, Kuliev A: Preimplantation diagnosis for p53 tumour suppressor gene mutations. Reprod Biomed Online 2001, 2:102-105.

8. Spits C, De Rycke M, Van Ranst N, Verpoest W, Lissens W, Van Steirteghem A,
Liebaers I, Sermon K: Preimplantation genetic diagnosis for cancer predisposition syndromes. Prenat Diagn 2007, 27:447-456.

9. Kuliev A, Rechitsky S, Verlinsky O, Tur-Kaspa I, Kalakoutis G, Angastiniotis M, Verlinsky Y: Preimplantation diagnosis and HLA typing for haemoglobin disorders. Reprod Biomed Online 2005, 11:362-370.

10. Verlinsky Y, Rechitsky S, Sharapova T, Laziuk K, Barsky I, Verlinsky O, Tur-Kaspa I, Kuliev A: Preimplantation diagnosis for immunodeficiencies. Reprod Biomed Online 2007, 14:214-223.

11. Van de Velde H, De Rycke M, De Man C, De Hauwere K, Fiorentino F, Kahraman S, Pennings G, Verpoest W, Devroey P, Liebaers I: The experience of two European preimplantation genetic diagnosis centres on human leukocyte antigen typing. Hum Reprod 2009, 24:732-740.

12. Devolder K: Preimplantation HLA typing: having children to save our loved ones. J Med Ethics 2005, 31:582-586.

13. Steffann J, Frydman N, Gigarel N, Burlet P, Ray PF, Fanchin R, Feyereisen E, Kerbrat V, Tachdjian G, Bonnefont JP, Frydman R, Munnich A: Analysis of mtDNA variant segregation during early human embryonic development: a tool for successful NARP preimplantation diagnosis. J Med Genet 2006, 43:244-247.

14. Tajima H, Sueoka K, Moon SY, Nakabayashi A, Sakurai T, Murakoshi Y, Watanabe H, Iwata S, Hashiba T, Kato S, Goto Y, Yoshimura Y: The development of novel quantification assay for mitochondrial DNA heteroplasmy aimed at preimplantation genetic diagnosis of Leigh encephalopathy. J Assist Reprod Genet 2007, 24:227-232.

15. Poulton J, Bredenoord AL: 174th ENMC international workshop: Applying pre-implantation genetic diagnosis to mtDNA diseases: implications of scientific advances 19-21 March 2010, Naarden, The Netherlands. Neuromuscul Disord 2010, 20:559-563.

16. Poulton J, Chiaratti MR, Meirelles FV, Kennedy S, Wells D, Holt IJ: Transmission of mitochondrial DNA diseases and ways to prevent them. PLoS Genet 2010, 6pii:e1001066.

17. Bredenoord AL, Dondorp W, Pennings G, De Die-Smulders CE, De Wert G: PGD to reduce reproductive risk: the case of mitochondrial DNA disorders. Hum Reprod 2008, 23:2392-2401

18. Bredenoord A, Dondorp W, Pennings G, de Die-Smulders C, Smeets B, de Wert G: Preimplantation genetic diagnosis for mitochondrial DNA disorders: ethical guidance for clinical practice. Eur J Hum Genet 2009, 17:1550-1559.

19. Liebaers I, Sermon K, Staessen C, Joris H, Lissens W, Van Assche E, Nagy P, Bonduelle M, Vandervorst M, Devroey P, Van Steirteghem A: Clinical experience with preimplantation genetic diagnosis and intracytoplasmic sperm injection. Hum Reprod 1998, 13:186-195.

20. De Vos A, Van Steirteghem A: Aspects of biopsy procedures prior to preimplantation genetic diagnosis. Prenat Diagn 2001, 21:767-780.

21. Verlinsky Y, Ginsberg N, Lifchez A, Valle J, Moise J, Strom CM: Analysis of the first polar body: preconception genetic diagnosis. Hum Reprod 1990, 5:826-829.

22. Joris H, De Vos A, Janssens R, Devroey P, Liebaers I, Van Steirteghem A: Comparison of the results of human embryo biopsy and outcome of PGD after zona drilling using acid Tyrode medium or a laser. Hum Reprod 2003, 18:1896-1902.

23. De Vos A, Staessen C, De Rycke M, Verpoest W, Haentjens P, Devroey P, Liebaers I, Van de Velde H: Impact of cleavage-stage embryo biopsy in view of PGD on human blastocyst implantation: a prospective cohort of single embryo transfers. Hum Reprod 2009, 24:2988-2996.

24. Barbash-Hazan S, Frumkin T, Malcov M, Yaron Y, Cohen T, Azem F, Amit A, Ben-Yosef D: Preimplantation aneuploid embryos undergo self-correction in correlation with their developmental potential. Fertil Steril 2009, 92:890-896

25. McArthur SJ, Leigh D, Marshall JT, de Boer KA, Jansen RP: Pregnancies and live births after trophectoderm biopsy and preimplantation genetic testing of human blastocysts. Fertil Steril 2005, 84:1628-1636.

26. Kokkali G, Traeger-Synodinos J, Vrettou C, Stavrou D, Jones GM, Cram DS, Makrakis E, Trounson AO, Kanavakis E, Pantos K: Blastocyst biopsy versus cleavage stage biopsy and blastocyst transfer for preimplantation genetic diagnosis of beta-thalassaemia: a pilot study. Hum Reprod 2007, 22:1443-1449.

27. McArthur SJ, Leigh D, Marshall JT, Gee AJ, De Boer KA, Jansen RP: Blastocyst trophectoderm biopsy and preimplantation genetic diagnosis for familial monogenic disorders and chromosomal translocations. Prenat Diagn 2008, 28:434-442. 
28. Moutou C, Gardes N, Nicod JC, Viville S: Strategies and outcomes of PGD of familial adenomatous polyposis. Mol Hum Reprod 2007, 13:95-101.

29. Spits C, De Rycke M, Verpoest W, Lissens W, Van Steirteghem A, Liebaers I, Sermon K: Preimplantation genetic diagnosis for Marfan syndrome. Fertil Steril 2006, 86:310-320.

30. lacobelli M, Greco E, Rienzi L, Ubaldi F, Podini D, Nuccitelli A, Tesarik J, Baldi M, Fiorentino F: Birth of a healthy female after preimplantation genetic diagnosis for Charcot-Marie-Tooth type X. Reprod Biomed Online 2003 7:558-562.

31. Traversa MV, Carey L, Leigh D: A molecular strategy for routine preimplantation genetic diagnosis in both reciprocal and Robertsonian translocation carriers. Mol Hum Reprod 2010, 16:329-337.

32. Fiorentino F, Kokkali G, Biricik A, Stavrou D, Ismailoglu B, De Palma R, Arizzi L, Harton G, Sessa M, Pantos K: Polymerase chain reaction-based detection of chromosomal imbalances on embryos: the evolution of preimplantation genetic diagnosis for chromosomal translocations. Fertil Steril 2010. doi:10.1016/j.fertnstert.2009.12.063.

33. Coskun S, Alsmadi O: Whole genome amplification from a single cell: a new era for preimplantation genetic diagnosis. Prenat Diagn 2007, 27:297-302.

34. Spits C, Le Caignec C, De Rycke M, Van Haute L, Van Steirteghem A, Liebaers I, Sermon K: Whole-genome multiple displacement amplification from single-cells. Nat Protoc 2006, 1:1965-1970.

35. Höckner M, Erdel M, Spreiz A, Utermann G, Kotzot D: Whole genome amplification from microdissected chromosomes. Cytogenet Genome Res 2009, 125:98-102

36. Renwick P, Trussler J, Lashwood A, Braude P, Ogilvie CM: Preimplantation genetic haplotyping: 127 diagnostic cycles demonstrating a robust, efficient alternative to direct mutation testing on single-cells. Reprod Biomed Online 2010, 20:470-476.

37. Johnson DS, Gemelos G, Baner J, Ryan A, Cinnioglu C, Banjevic M, Ross R, Alper M, Barrett B, Frederick J, Potter D, Behr B, Rabinowitz M: Preclinical validation of a microarray method for full molecular karyotyping of blastomeres in a 24-h protocol. Hum Reprod 2010, 25:1066-1075.

38. Treff NR, Su J, Tao X, Miller KA, Levy B, Scott RT Jr: A novel single-cell DNA fingerprinting method successfully distinguishes sibling human embryos. Fertil Steril 2010, 94:477-484.

39. Wells D, Escudero T, Levy B, Hirschhorn K, Delhanty J, Munné S: First clinical application of comparative genomic hybridisation and polar body testing for preimplantation genetic diagnosis of aneuploidy. Fertil Steril 2002, 78:543-549.

40. Voullaire L, Slater H, Williamson R, Wilton L: Chromosome analysis of blastomeres from human embryos by using CGH. Hum Genet 2000, 106:210-217.

41. Wilton L, Williamson R, McBain J, Edgar D, Voullaire L: Birth of a healthy infant after preimlantation confirmation of euploidy by comparative genomic hybridisation. N Engl J Med 2001, 345:1537-1541.
42. Wells $D$, Brynn L: Cytogenetics in reproductive medicine: the contribution of comparative genomic hybridisation (CGH). BioEssays 2003, 25:289-300.

43. Le Caignec, C, Spits C, Sermon K, De Rycke M, Thienpont B, Debrock S, Staessen C, Moreau Y, Fryns JP, Van Steirteghem A, Liebaers I, Vermeesch, JR: Single-cell chromosomal imbalances detection by array CGH. Nucleic Acids Res 2006, 34:e68.

44. Munne S, Ketterson K, Wagner C, Hill D, Cohen J, Wells D: Pregnancy outcome following comprehensive chromosome analysis at the cleavage and blastocyst stages. Fertil Steril 2010, 94:S175-S176.

45. Scriven PN, Bossuyt PM: Diagnostic accuracy: theoretical models for preimplantation genetic testing of a single nucleus using the fluorescence in situ hybridization technique. Hum Reprod 2010, 25:2622-2628.

46. Wilton L, Thornhill A, Traeger-Synodinos J, Sermon KD, Harper JC: The causes of misdiagnosis and adverse outcomes in PGD. Hum Reprod 2009, 24:1221-1228

47. Thornhill AR, De Die-Smulders CE, Geraedts JP, Harper JC, Harton GL, Lavery SA, Moutou C, Robinson, MD, Schmutzler AG, Scriven PN, Sermon KD, Wilton $L$ : ESHRE PGD Consortium "Best practice guidelines for clinical preimplantation genetic diagnosis (PGD) and preimplantation genetic screening (PGS)". Hum Reprod 2005, 20:35-48.

48. Preimplantation Genetic Diagnosis International Society: The Preimplantation Genetic Diagnosis International Society (PGDIS): Guidelines for good practice in PGD. Reprod Biomed Online 2004, 9:430-434.

49. Preimplantation Genetic Diagnosis International Society (PGDIS): Guidelines for good practice in PGD: programme requirements and laboratory quality assurance. Reprod Biomed Online 2008, 16:134-147.

50. Corveleyn A, Morris MA, Dequeker E, Sermon K, Davies JL, Antiñolo G, Schmutzler A, Vanecek J, Nagels N, Zika E, Palau F, Ibarreta D: Provision and quality assurance of preimplantation genetic diagnosis in Europe. Eur $J$ Hum Genet 2008, 16:290-299.

51. Vendrell $X$, Carrero R, Alberola T, Bautista-Llácer R, García-Mengual E, Claramunt R, Pérez-Alonso M: Quality management system in PGD/PGS: now is the time. J Assist Reprod Genet 2009, 26:197-204.

52. Harper JC, Sengupta S, Vesela K, Thornhill A, Dequeker E, Coonen E, Morris MA: Accreditation of the PGD laboratory. Hum Reprod 2010, 25:1051-1065.

53. The UK National External Quality Assessment Service (UKNEQAS) [http:// www.ukneqas-molgen.org.uk]

54. The Cytogenetics European Quality Assessment Service (CEQA) [http:// www.ceqa-cyto.eu]

doi:10.1186/gm195

Cite this article as: De Rycke M: Singling out genetic disorders and disease. Genome Medicine 2010, 2:74 